histology, and is worthy of a fuller description than we have in the book before us. As a matter of fact the histological examination of the brain and cord of such cases is an education in itself.

The work can be recommended as a new phase in British neurological literature. We required a book of this nature in English, and it is welcome ; but if, in the future, the authors can see their way to enlarge on the subject and lay down the problems, in so far as we know them at present, which concern neurological research, one can predict a much larger sphere of usefulness for a volume which lends itself so naturally to expansion. In conclusion, one would remark that the subject matter is clearly expressed, and that the illustrations are excellent.

I). OrR.

Instinct and the Unconscious: a Contribution to a Biological Theory of the Psychoneuroses. By W. H. R. Rivers, M.D., Fellow and Praclector in Natural Science, St. John's College, Cambridge. Second cdition. 'Large 8vo. Pp. viii $+27 \%$. 1922. Cambridge: University Press. 16s. net.

'ThF: second edition of Dr. Rivers' book does not differ in marked degree from the first, save in the addition of two new appendices; its appearance is a proof of the popularity of an attempt to compare the functional disorders of mind and nervous system with the concepts held by biologists and physiologists.

Such a book may be analyzed either from the standpoint of the psychologist or from that of the physiologist, and it is from the latter that this present review is written. It may be said at once that, brilliant as the psychological reasoning contained in the work may be, the physiological treatment of the subject is by no mcans free from criticism.

Dr. Rivers treats first of the 'unconscious' and then of 'suppression'. His definitions are not very exact, and it would appear that the word 'unconscious' is used as an adjective to qualify that experience which cannot be brought into the field of consciousness by any ordinary process of memory or association. Again, 'the unconscious' appears to be composed in part of such unavailable experience (if we interpret aright). 'Suppression' is that process by which experience becomes unconscious.

Here, then, we have two things---experience and the suppression of experience. It appears to be Dr. Rivers' argument that the experience which is suppressed is painful experience, and that the suppression occurs because of the discomfort which would otherwise be incurred. He goes so far as to say (p. 20) that the experience which tends to be forgotten or repressed is the immediately painful. As the word 'repression' denotes here a conscious process, we must infer that those things which are put out of the mind are usually painful. This is probably incorrect. The writer of this review finds (in common with many others) that the major part of active repression in everyday life is occupied in putting away the memories of pleasant expcrience-green ficlds and streams-that the mind may concentrate upon its problems.

The biological portion of the book is mainly occupied in the finding of 
physiological parallels for 'suppression' and in an inquiry into the nature of that which is suppressed. Dr. Rivers proceeds from the lower levels upwards. In an attempt to find a relationship between psychological 'suppression' and physiological 'inhibition', he first takes Dr. Henry Head's views of the afferent nervous system and accepts the distinction between protopathic and epicritic sensibility. In this connection he describes some observations which may be interpreted in terms of the inhibition of the former by the latter, and commits himself to the statement (p. 27) that this is "the cxpression of a purely physiological process in the peripheral [sic] nervous system". Still keeping to the afferent nervous system, Dr. Rivers next states that there is a relation between the cerebral cortex and the optic thalamus similar to that between the epicritic and protopathic afferent nervous systems.

Turning then to the reflex, he states that " the whole process is immediate and incapable of modification" (p. 28), and proceeds to a discussion of the results of Head and Riddoch. In these he again finds a parallel to psychological suppression. 'The 'mass-reflex' described by these observers is a "peculiar form of reflex with characters unknown when the nervous system is intact" (p. 28). This reflex is wholly suppressed in the normal man, and appears in cases of transverse lesion of the spinal cord when it is released from the control of the higher parts of the nervous system. The conclusion at which the author arrives is that the suppression of conscious experience is only one example of a widespread process - the universal physiological property of inhibition. The 'unconscious' now becomes re-defined as that which has required to be suppressed.

What is this which is suppressed to form the unconscious? It is experience of a particular nature-experience which has been accompanied by strong emotional tone; so, at any rate, Dr. Rivers deduces from the examples of suppression which he selects to illustrate his argument. But he points out that much of the detail which may be forgotten or suppressed is of neutral emotional tone, and he assumes that the suppressed experience carries associated experiences with it into the unconscious. He posits a close relation between emotion and instinct, and comes to the conclusion that the content of the unconscious is made up of feelings and affects which form the conscious aspect of instinctive reactions and tendencies, and of sensory and intellectual elements which have been associated with these reactions.

It now becomes necessary to inquire into the nature of instinct. It is, however, the case that no attempt is made to tell us what the author means by this word-although various properties of instinct are postulated. Instinct appears to be something which is innate and different from intelligence (which is acquired). Emotions, such as fear or anger, are expressions of instinct; and bchaviour which can be ascribed to instinct tends to be of 'all-or-none' character. Great play is made with this 'all-or-none' principle. Ardian's experiment on peripheral nerve is described; the 'all-or-none' principle is stated to apply ('practically') to protopathic sensibility; the reactions of an animal exposcd to danger are stated to 'tend' to be maximal or nothing (p. 44 ); of all the spinal reflexes, he selects 
Sherrington's 'extensor thrust' as exhibiting the 'all-or-none' character [this relatively unimportant reflex is almost the only example the author selects out of the domain of experimental physiology, and he ignores the fact that the majority of spinal reflexes are characterized by properties of fine gradation]; the 'mass-reflex' is again cited ; even the 'all-or-none' contraction of heart muscles is used in the argument-as of especial importance owing to the close relations between the heart and affective disturbances, and with a complete ignoring of the finer variations which occur in the frequency of the heart beat.

As a result of this argument a conclusion with regard to the characteristics of a certain class of instincts is attained. These are such that they exhibit an absence of exactness of discrimination, of appreciation, and of graduation of response. A final analogy is obtained from the work of Head and Holmes, who are stated to have 'shown' the essential nucleus of the optic thalamus to be the central basis of emotive reactions, for which the above characteristics hold good. [It is worthy of note that the reactions in question were largely speech reactions!] Dr. Rivers then takes the bold step of calling this class of instinctive reactions 'protopathic', and the remaining instinctive reactions 'epicritic'.

Dr. Rivers next seeks a reason for suppression of certain experience. He thinks that some of the instinctive reactions are subject to the 'all-ornone' principle, and states (p. 61) that " even in man there is no graduation of the rapidity and length of a flight accompanied by definite fear" !. Unless these instincts are suppressed, the manipulative reactions (such as the direction of an aeroplane or the shooting of an arrow) will be inefficient. Hence the accurate discrimination necessary for continued life calls for a suppression of the thorough-going 'all-or-none' instincts. This surmise leads to an interesting speculation with regard to the evolution of man. It is assumed that at one time his ancestors took to an arboreal life. Before this, they removed themselves from danger by flight along the groundflight which consists in the simple and wholly instinctive movements of running. With the tree life there arose more delicate and discriminative adjustments of eyes and limbs, made necessary by the different complexities of their new environment. But surely the ground was then no even surface like a garden lawn, and surely it called for as delicate and accurate 'discriminations' as the branches of a forest?

We have now covered the main part of the physiological argument of the book. It presents an interesting speculation, made not the less interesting for the author's obvious enthusiasm for his subject. As a mere speculation it might stand; but if it is seriously put forward to be a true picture of our physiological views and a reasoned statement from the standpoint of exact science, a more close analysis must be made.

Unsatisfying features of the physiological side of the book are presented by the author's use of terms, by his description and selection of facts, and by the method of his argument.

With regard to terms, a marked feature of the book is the absence of exact definition and the attachment of different meanings to the same word. Thus the word 'reaction' appears to be used in the physical sense in one 
place (p. 53, 54) where it is applied (as 'instinctive reaction') to the acts of flight and of crying; but in another place (p. 49) it appears to be used in a psychological sense where 'instinctive reactions are buried within the unconscious'. Occasionally we find a comparison of incompatibles, as (p. 17) where 'suppression' is said to occur as a result of physical or mental shock-a psychological function conditioned either by a physical or by a psychological stimulus!

It will be seen, from our description of Dr. Rivers' argument, that he builds it up by comparing a series of selected observations. But a closer investigation demonstrates the fact that the foundations upon which he builds are largely speculative, and that he makes little or no effort to secure their stability.

Thus, Dr. Henry Head's views on the mechanism of the afferent nervous system-with its protopathic and epicritic divisions-are at the very basis of the argument. The results have been challenged by Boring (1916), and have been reasserted by Head. So important is Head's view to the argument of the book that the writer might well have referred to the challenge and given his reasons for setting it aside. Again, weight is given to the views of Head and Holmes on the function of the optic thalamus. Careful as the work of these two observers is, the conclusions to which they come are speculative; their localization of a particular function in the thalamus is only one of many possibilities, and the others have not been excluded. Such a foundation is insecure. Ardian's 'all-or-none' experiment is inaccurately described, and the reader finds that what is really a possible inference from the experiment is stated as a scientific finding which is used in the argument of the book.

In view of the admittedly close relation between 'instinctive' and reflex reaction (p. 38), we would have expected a considerable discussion of the spinal reflex. Out of this great field the author selects merely the 'extensor thrust' (an 'all-or-none' reflex) and ignores the occurrence of the multitude of graduated reflexes. The scratch-reflex with its gradation in local sign and in intensity, the flexion-reflex with its minute gradation in intensity, the finely-graded proprioceptive reflexes, all are alike ignored. The author confines himself almost entirely to the 'mass-reflex' as described in spinal man by Head and Riddoch. As regards the limb-movement component of this reaction, we are merely dealing with the flexion-reflex as described by Sherrington. This exhibits little or no variation with variation in the locus of the stimulus, but a very fine gradation with variation in the intensity of the stimulus-it is the worst example of 'all-or-none' reaction which could be selected. Nevertheless Dr. Rivers fixes his attention on the absence of local signature (p. 28), and states that there is complete absence of relation between intensity of stimulus and reaction in the case of the mass-reflex (flexion-reflex ?) which he classes as an 'all-or-none' reaction! A broader selection of examples of reflex action would have shown an absence of the 'all-or-none' principle in the greater number of them.

The mode of argument used in the book is largely that of special pleading. An instance may be given in the use of the word 'suppression' which 
denotes "the process by which experience becomes unconscious" (p. 17). In the fourth chapter of the book an attempt is made to show that suppression is related to certain physiological processes (p. 22)--in short, to inhibition (p. 31). Yet the author persistently uses the word 'suppression' for the physiological 'inhibition' throughout the chapter in which he is attempting to show that the two processes are similar, thus suggesting to the reader that which he tries to prove. To speak at one place of the suppression of psychological experience (p. 22), and at another of " experience suppressed on the sensorimotor and reflex levels" (p. 3t), seems to be a misuse of terms.

Another aspect of this mode of argument is the exaltation of theory until it becomes equal in value to fact. Perhaps becomes is ; nearly changes into quite, as the argument proceeds. Thus the author states (p. 46) that it would strengthen his argument if it could be shown that protopathic sensibility obeys the "all-or-none' principle. He finds that this is " practically, though not completely, the case". Yet on the next page it turns out that any exact relation between stimulus and reaction is 'wholly' absent in the case of protopathic sensibility. Again, it is the author's thesis that suppression especially (or even 'only') oceurs when the emotions have been strongly aroused (p. 35). Yet he admits that much of the experienee suppressed is of a 'neutral' (that is, unemotional) kind. 'This is a crux ; and to remove it, he assumes as " at least a legitimate hypothesis that this experience has come to form part of the content of the unconscious on account of its association with experience which needed suppression because of its painful nature" (p. 36). Yet on the following page this hypothesis takes on the habit of fact ; for we read that "it has been found that experience which becomes unconscious through the agency of suppression either belongs definitely to the affective aspect of mind or, when intellectual in character, has been suppressed on account of its association with affective elements". There is no attempt in the intervening paragraphs to remove this speculation to the realm of fact.

It is perhaps ungenerous to criticize a book which is so pleasant to read and so stimulating in its thought. But the book is a frank attempt to bring psychological and biological concepts into relation onc with another. This aim naturally suggests that the physiological prescntation is made in the strict convention of exact science. The great reliance here placed upon the value of hypothesis and theory is not part of that convention; and the author's attitude may perhaps be surmised from a statement which he makes in his introductory chapter. There, writing of pathological mechanisms and causes, he states (p. 4) that "few will find it worth while to study the details of a structure [i.c., mechanisms] resting upon foundations [i.c., causes and conditions] they reject". This statement appears to glorify theory to such an extent as to suggest that few investigators will apply themselves to facts if they are uncertain of the theory. Yet it is just in these very circumstances that the investigation of facts becomes of greatest interest. The advance of physiology occurs because of (and not in spite of) distrust and dissatisfaction; theory and hypothesis are temporary scaffolding, the servants of science, not its mistresses. 
The book is really a tour de force written in the psychological convention. Sclected physiological facts are used ; but they are treated in the psychological manner. The chicf importance of the book lies in its mental stimulation ; and it may well point a way towards a physiological treatment of the data obtained by psychologists.

T. Graham Brown.

\section{Morbid Fears and Compulsions: their Psychology and Psycho-analytic} Treatment. By H. W. Frink, M.D., Assistant Professor of Neurology in Cornell University Medical College. With an Introduction by James J. Putram, M.D., Emeritus Professor of Neurology, Harvard University. Pp. xxiii + 344. 1921. London : Kegan Paul, Trench, Trübner \& Co. Ltd. 21s. net.

THE majority of books on psycho-analysis are cither written on popular lines, presumably for the layman, or else they consist of a collection of papers or lectures which fail to give a systematic account of the subject. Such criticisms are not applicable to this volume, as it provides a fairly comprehensive account of Freud's psychology, and is written for those who already know something about psycho-analysis and are desirous of learning more, with the intention, in some instances, of using it in practice. The carlier chapters are devoted to the more theoretical aspects of psychoanalysis, and give an account of the infantile sexual theories, the unconscious, repression, the pleasure principle, dream psychology, the mechanisms of psychopathological manifestations, and the neurosis as a whole. Then follows an account of the actual analysis of a case of compulsion neurosis which occupies a whole chapter of seventy-three closely-printed pages. The various stages in the analysis are clearly described, but it does not demonstrate, as the author himself subsequently points out, the influence of the infantile sexual factor in the production of the neurosis. Another criticism which suggests itself is that concerning the memories of the patient clicited by the analysis. These do not appear to have required any special technique to bring them into consciousness, and the question naturally arises as to what the psycho-analyst really means by repression, resistance, and the content of the unconscious. Though the analysis enabled the patient to correlate her various experiences with her morbid symptoms, it does not appear that these experiences were inacessible to consciousness even at the beginning of the treatment. On the contrary, the final 'secret' clicited could have been revealed at the first, and it was deliberately concealed, rather than rendered 'unconscious' in the Freudian sense. This comment is made, not with the purpose of questioning the value of the psycho-analytic procedure as a means of straightening the tangles of the mind of a psycho-ncurotic, but rather with the view of questioning the validity of the distinctions made between memories out of the focus of attention at any given moment, those which are suppressed, and those which are repressed or unable to be recalled. The author does not make these points at all clear in his theoretical discussions, and many of his readers will probably find his conception of a structural unconscious rather 